\title{
TUBERCULOUS PERICARDIAL CALCIFICATION
}

\author{
M. M. Nayak' ${ }^{1}$ P. V. Potdar², H. S. Thakker ${ }^{3}$
}

HOW TO CITE THIS ARTICLE:

M. M. Nayak, P. V. Potdar, H. S. Thakker. "Tuberculous Pericardial Calcification”. Journal of Evolution of Medical and Dental Sciences 2014; Vol. 3, Issue 74, December 29; Page: 15614-15616,

DOI: $10.14260 /$ jemds $/ 2014 / 4108$

INTRODUCTION: Pericardial tuberculosis remains a major problem in $3^{\text {rd }}$ world countries. It is estimated to account for $70 \%$ of large pericardial effusions \& most cases of constrictive pericarditis in developing countries.(1,2)

A 55 year old male presented with dyspnea on exertion and anasarca since 2 months. The patient had history of right sided pleural effusion 4 years ago and approximately $200 \mathrm{cc}$ of fluid had been aspirated. The patient had not taken anti-tubercular treatment in the past.

On examination the patient had bilateral pedal edema, raised JVP, hepatomegaly, ascites, and findings suggestive of right sided pleural effusion. Clinical features were suggestive of congestive heart failure.

Chest X-ray (frontal \& lateral) showed right sided pleural effusion and pericardial calcification. These findings were confirmed on CT. Pleural aspiration revealed thick pus. Pericardial calcification prompted us to consider constrictive pericarditis as one of the differential diagnosis. ECG revealed low voltage and T wave inversion, USG abdomen confirmed hepatomegaly \& ascites. There was no evidence of portal hypertension. 2-D Echo revealed thick and calcified pericardium, septal bounce was not noted, IVC was not dilated but was not collapsing. Mitral E wave deceleration time was normal.

Fig. 1(a): Chest X-ray (Frontal view) shows thick pericardial calcification along left cardiac border and inferior cardiac border along with right pleural effusion.

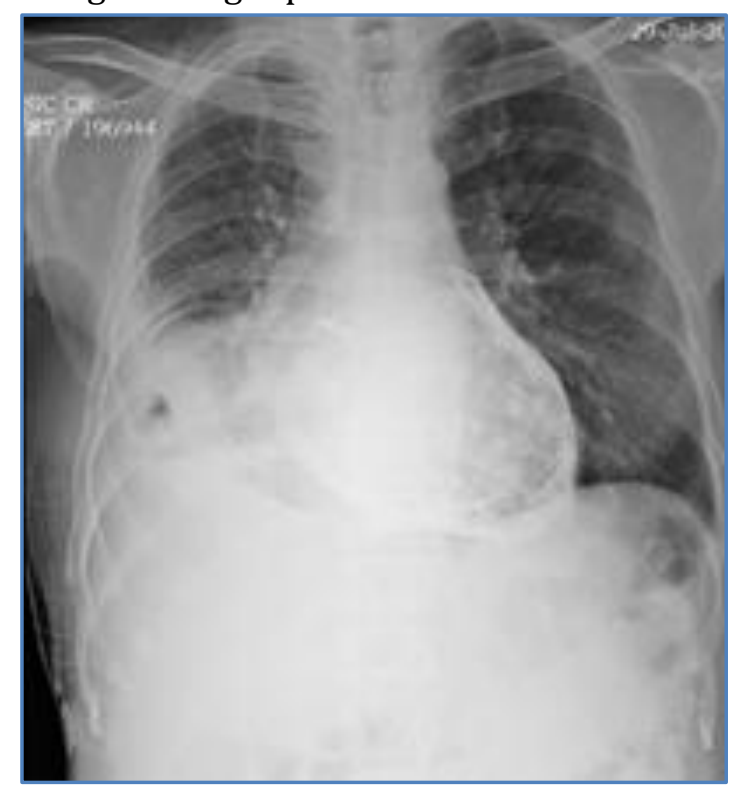

Fig. 1(a) 
Fig. 1(b): Chest X-ray (lateral view) shows thick pericardial calcification over both the ventricles \& Inter costal drainage tube in situ.

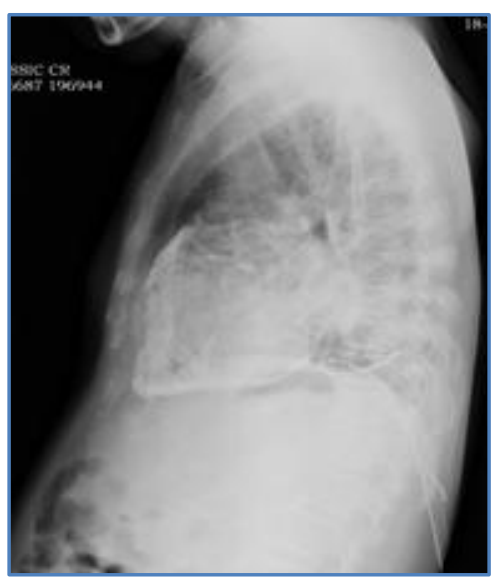

\section{Fig. 1(b)}

Fig. 2(a), Fig. 2(b), Fig. 2(c): CT chest showing encysted pleural effusion on the right side, circumferential calcification of the pericardium involving right ventricle, left ventricle \& inferior pericardium.

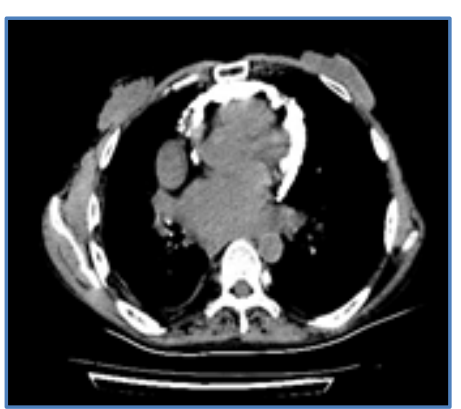

Fig. 2(a)

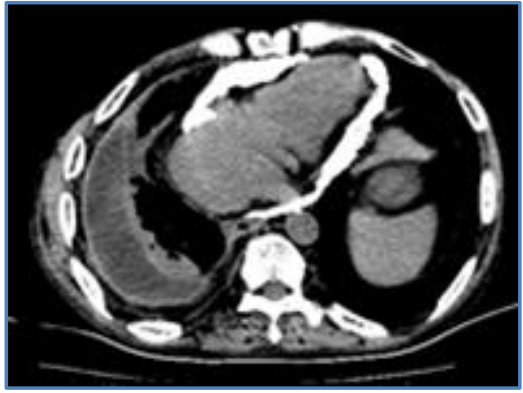

Fig. 2(b)

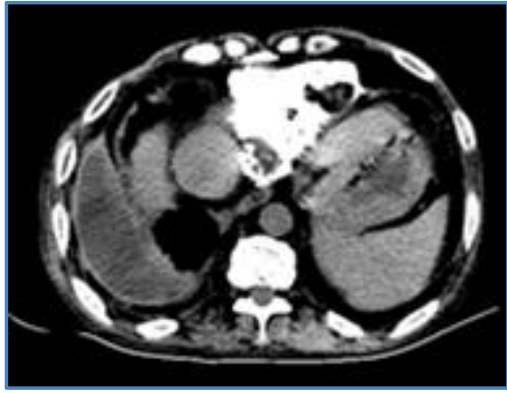

Fig. 2(c)

\section{Pleural fluid analysis showed:}

1. Pleural fluid Proteins 4.1gm/dl.

2. Pleural fluid sugar $35 \mathrm{mg} / \mathrm{dl}$.

3. Pleural fluid LDH $934 \mathrm{IU} / \mathrm{L}$.

4. Pleural fluid ADA 70U/L.

5. Smear negative for Acid Fast Bacilli

6. Pleural fluid TB-PCR was POSITIVE.

Tubercular etiology was strongly considered due to past history of undiagnosed pleural effusion. Strongly positive Montoux test $(18 \mathrm{~mm})$ and microscopy and culture of aspirated pus being negative for pyogenic / fungal culture.

Patient was started on anti-tubercular regimen and and inter-costal drain was inserted to drain the pus from the pleural cavity. 
Patient has been recently started on anti-tubercular treatment and is currently stable clinically.

Calcification of pericardium is usually preceded by an episode of pericarditis or trauma. On chest radiograph pericardial calcification appears as a curvilinear calcification usually affecting the right side of the heart. It is often visualized better on a lateral chest x-ray than on frontal view.

Calcification associated with tuberculous pericarditis presents as thick amorphous calcification along the atrio-ventricular groove. The calcium may then spread from the grooves over the surfaces of the atria and the ventricles. This pattern is observed less often with other forms of pericarditis. ${ }^{(3,4,5,6)}$

Pericardial calcification can be detected on chest radiograph in about half of the cases of constrictive pericarditis. However, extensive pericardial calcification can be present without signs and symptoms of constrictive pericarditis. Although there are many causes of pericardial constriction, tuberculosis has historically been the leading cause worldwide.

\section{REFERENCES:}

1. Mayosi BM, Burgess LI, Doubell AF: Tuberculous pericarditis. Circulation 112, 3608, 2005.

2. Syed FF, Mayosi BM,: A modern approach to Tuberculous pericarditis, prog cardiovascular Dis., 50: 218, 2007.

3. Jefferson k, Rees S. calcification.In: Jefferson K, Rees S, Editors clinical cardiac radiology. $2^{\text {nd }}$ ed. London: Butterworth: 1980.p.76-87.

4. Mac Gregor JH, Chen JTT, Chiles $\mathrm{C}$, et al. The radiographic distinction between pericardial and myocardial calcification. AJR Am J Roentgenol1987: 148: 675-7.

5. Shawdon HH, Dinsmore RE. pericardial clacification: radiologic features and clinical significance in twenty six patients. Clin Radiol 1967:18:205-12.

6. Ling LH, Oh JK, Breen JF, et al. calcific constrictive pericarditis: is it still with us? Ann Intern Med 2000:132: 444: 50.

\section{AUTHORS:}

1. M. M. Nayak

2. P. V. Potdar

3. H. S. Thakker

\section{PARTICULARS OF CONTRIBUTORS:}

1. Professor, Department of Respiratory Medicine, Mahatma Gandhi Mission's Hospital and Medical College.

2. Professor and HOD, Department of Respiratory Medicine, Mahatma Gandhi Mission's Hospital and Medical College.

3. $3^{\text {rd }}$ Year Junior Resident, Department of Respiratory Medicine, Mahatma Gandhi Mission's Hospital and Medical College.
NAME ADDRESS EMAIL ID OF THE CORRESPONDING AUTHOR:

Dr. M. M. Nayak,

Professor,

Department of Respiratory Medicine, Mahatma Gandhi Mission's Hospital \& Medical College, Sector 1, Kamothe, Navi Mumbai-410209.

E-mail: drmmnayak@gmail.com

Date of Submission: 05/12/2014. Date of Peer Review: 06/12/2014. Date of Acceptance: 20/12/2014. Date of Publishing: 29/12/2014. 